\title{
Low dose danazol in the treatment of the premenstrual syndrome
}

\author{
Miriam Deeny, Robert Hawthorn and D. McKay Hart
}

Division of Obstetrics and Gynaecology, Stobhill General Hospital, Glasgow G21 3UW, UK.

\begin{abstract}
Summary: This double-blind, randomized, crossover study compared the efficacy and safety of danazol (100 $\mathrm{mg}$ twice daily) with matching placebo in the treatment of severe premenstrual syndrome. Nineteen patients were randomly allocated to receive danazol for 3 months followed by placebo, and 18 to receive treatment in the reverse order.

Assessments of overall condition showed improvement to be statistically significantly more likely with danazol than with placebo $(P<0.001)$ after 3 months' treatment. Furthermore, daily visual analogue scale assessments demonstrated statistically significantly better premenstrual scores with danazol in comparison to placebo for breast discomfort, irritability, depression, anxiety, mood swings, crying, depressed libido and abdominal swelling.

It is concluded that danazol provides effective and generally well tolerated treatment for severe premenstrual syndrome.
\end{abstract}

\section{Introduction}

The aetiology of the premenstrual syndrome (PMS) is not yet clearly defined and therefore the appropriate therapy for this condition is still debated. However PMS is evidently related to the menstrual cycle, ${ }^{1}$ therefore agents which affect this cycle, may have a part to play in the treatment of the condition.

Whilst danazol, a derivative of ethisterone, has been shown to be effective at a dosage of $400 \mathrm{mg}$ / day $^{2}$ side effects, particularly suppression of menstruation, were not infrequent. A subsequent pilot study suggested that a dosage of $200 \mathrm{mg}$ /day is effective and is likely to prove more acceptable than $400 \mathrm{mg} /$ day. $^{3}$ This study was therefore undertaken to more clearly define the efficacy and tolerability of the lower dose.

\section{Material and methods}

\section{Study design}

A double-blind, randomized crossover comparison of danazol (100 mg twice daily) with matching placebo was undertaken. Patients considered to be suffering from severe PMS were recruited from the PMS clinic at Stobhill General Hospital, Glasgow.

Correspondence: D.M. Hart, M.D., F.R.C.S., F.R.C.O.G. Accepted: 29 October 1990
Informed consent and Ethics Committee approvî요 were obtained.

During a 2-month baseline, patients made dai linear analogue estimates of the severity of the following symptoms: breast discomfort, irritability, depression, anxiety, fluid retention, abdominal swelling, headache, mood swings, depressed libido, crying and increased appetite.

Each $10 \mathrm{~cm}$ scale ranged between the two extremes, no symptom and worst every symptom. Suitability for the study was confirmed if there was significant worsening of symptoms in the premenstrual phase, relief soon after the onset of menstruation, and the patient complained of consequent social impairment.

The following exclusion criteria applied: age under 18 years; weight under $45 \mathrm{~kg}$ or over $80 \mathrm{~kg}$; sensitivity to or previous treatment with danazol; oral contraceptive within 3 months; concomitant corticosteroid, anticoagulant or hormone therapy, or medication for PMS; presence of epilepsy, $N$ migraine, diabetes, intermittent porphyria; car- $N$ diac, hepatic, renal or thyroid impairment; preg- $N$ nancy, unwillingness to use barrier contraception $\omega$ throughout study.

Patients were randomly allocated to receive $\stackrel{\varrho}{\subset}$ identical consecutive courses of either danazol $\Phi$ capsules $100 \mathrm{mg}$ twice daily, for 3 months, followed by placebo $(n=19)$ or vice versa $(n=18)$. Throughout treatment, patients were asked to $\mathbb{D}$

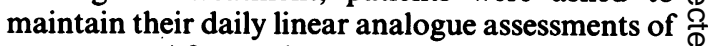
symptoms. After each course, patients were asked 
to assess their overall condition in relation to baseline using a standard 6 point scale (completely better to much worse), and were questioned about possible side effects. Other monitoring included blood pressure, weight, full blood count, and liver function tests.

\section{Statistical analysis}

The patients' assessments of overall condition were analysed using the methodology of Hills and Armitage $^{4}$ to determine whether there were any period or carry-over effects. No period or carryover effects were detected and the data from both treatment order groups were pooled.

The patients' daily symptom diaries yielded a 'premenstrual score' for each symptom, derived from its mean score over the 7 days of the premenstrual phase. Where menstruation was suppressed, a premenstrual phase was estimated under blind conditions from the average cycle length. In addition, a 'rest of cycle score' was derived from the mean of the daily scores for the whole cycle excluding the premenstrual phase. For the pretreatment (baseline) data 'premenstrual scores' were compared with 'rest of cycle scores' using the Wilcoxon two sample test.

Data for 'premenstrual' and 'rest of cycle' scores were pooled and comparisons made between the treatments using the Wilcoxon two sample test. The overall assessments of condition were compared between the treatment groups using the Chi-square test. Haematological and liver function data were compared for the two treatments using the $t$-test, and weight and blood pressure using the Wilcoxon two sample test. The 5\% significance level was used to test all hypotheses.

\section{Results}

\section{Study population}

Patient characteristics Table I demonstrates that the two treatment order groups were well balanced in terms of patient characteristics. Comparisons of baseline 'premenstrual' with 'rest of cycle' scores, demonstrated statistically significant premenstrual worsening in 9 of the 11 symptoms under study, thus confirming their relevance to premenstrual syndrome in this population.

Withdrawals Nine patients withdrew from danazol treatment, 4 because of side effects (weight gain -2 , nausea -1 , irregular bleeding -1 ), one as a consequence of psychosexual problems and 4 with- out explanation. Four patients withdrew from placebo, one because of worsening symptoms and 3 without explanation. Thus, 33 and 31. patients commenced treatment and 30 and 29 patients completed treatment, with danazol and placebo respectively. All data available relating to these patients were included in the analyses up to the point of withdrawal.

\section{Response to treatment}

The assessments of overall condition demonstrated that significantly greater improvement had been obtained with danazol than with placebo after 3 months treatment $(P<0.001)$. Thus, following treatment with danazol $89 \%$ of patients were improved ( 24 of 27 ), of whom 10 were completely better, compared with only $22 \%$ on placebo (6 of 27), of whom none was completely better.

The majority of specific symptoms also showed greater improvement with danazol. Thus, after 3 months of danazol treatment the 'premenstrual scores' for breast discomfort, irritability, depression, anxiety, mood swings, crying, depressed libido and abdominal swelling, were statistically significantly lower than after placebo (Table II).

No statistically significantly differences were seen in the 'rest of cycle scores', for any of the 11 symptoms assessed in the study. Furthermore, if only the 'premenstrual scores' relating to the last recorded menstruation on treatment are included in the analysis for those 10 patients who became amenorrheic on danazol, statistically significantly lower scores are still demonstrable during danazol compared with placebo treatment for abdominal swelling, anxiety, breast discomfort, depression, irritability, depressed libido and mood swings (see Table III).

\section{Safety}

Patients reports of adverse events are listed in Table IV. Overall, there were more complaints with danazol than with placebo but none was clinically serious. Commonest were altered menses, nausea and oily skin/spottiness. Other safety assessments, including blood pressure, full blood count, platelet count and liver function tests, demonstrated no changes of any clinical significance in any patient.

There were no statistically significant differences in weight between danazol and placebo treated groups at the end of the treatment. However, with danazol weight increased in 8 patients (by a maximum of $6 \mathrm{~kg}$ ), was unchanged in 6 and fell in 9 patients, of 23 who provided end of treatment data. With placebo, weight also rose in 11 patients (by a maximum of $12.5 \mathrm{~kg}$ ), was static in 1 and fell in 9 patients of 21 who provided end of treatment data. 
Table I Patient characteristics

\begin{tabular}{|c|c|c|c|c|c|c|}
\hline \multirow{3}{*}{$\begin{array}{l}\text { Admission } \\
\text { characteristics }\end{array}$} & \multicolumn{6}{|c|}{ Treatment order group } \\
\hline & \multicolumn{3}{|c|}{$\begin{array}{c}\text { Danazol-Placebo } \\
n=19\end{array}$} & \multicolumn{3}{|c|}{$\begin{array}{c}\text { Placebo-Danazol } \\
n=18\end{array}$} \\
\hline & Mean & s.d. & $n^{*}$ & Mean & s.d. & $n^{*}$ \\
\hline Age (years) & 35.4 & 4.9 & 19 & 34.9 & 6.0 & 18 \\
\hline Height $(\mathrm{cm})$ & 159.8 & 5.1 & 17 & 159.3 & 8.7 & 13 \\
\hline $\begin{array}{l}\text { Age at menarche } \\
\text { (years) }\end{array}$ & 13.7 & 2.1 & 19 & 12.8 & 1.7 & 15 \\
\hline Number of pregnancies & 2.9 & 1.9 & 19 & 2.3 & 1.6 & 18 \\
\hline Days bleeding & 5.2 & 1.7 & 19 & 5.8 & 1.9 & 18 \\
\hline Length of cycle (days) & 28.7 & 4.8 & 19 & 28.3 & 4.7 & 18 \\
\hline $\begin{array}{l}\text { Duration of PMS } \\
\text { (years) }\end{array}$ & 4.4 & 5.8 & 18 & 4.7 & 3.9 & 18 \\
\hline
\end{tabular}

* = number for which data available.

Table II Premenstrual scores: pooled data, irrespective of treatment order

\begin{tabular}{|c|c|c|c|c|c|}
\hline Symptom & $\begin{array}{c}\text { Baseline } \\
(n=35) \\
\text { Median } \\
\text { (range) }\end{array}$ & $\begin{array}{c}\text { Danazol } \\
(n=30) \\
\text { Median } \\
\text { (range) }\end{array}$ & $\begin{array}{c}\text { Placebo } \\
(n=29) \\
\text { Median } \\
\text { (range) }\end{array}$ & $\begin{array}{c}P \\
\text { Danazol } \\
\text { vs } \\
\text { Placebo }\end{array}$ & $\begin{array}{l}\text { Danazol } \\
\text { vs } \\
\text { Baseline }\end{array}$ \\
\hline Breast discomfort & $\begin{array}{c}19.4 \\
(0-96.6)\end{array}$ & $\begin{array}{c}2.3 \\
(0-79.4)\end{array}$ & $\begin{array}{c}20.9 \\
(0-96.4)\end{array}$ & 0.0004 & 0.0012 \\
\hline Irritability & $\begin{array}{c}23.3 \\
(0-97.6)\end{array}$ & $\begin{array}{c}4.8 \\
(0-78.1)\end{array}$ & $\begin{array}{c}22.1 \\
(1.7-98.6)\end{array}$ & 0.0010 & 0.0002 \\
\hline Depression & $\begin{array}{c}13.9 \\
(0-97.9)\end{array}$ & $\begin{array}{c}2.7 \\
(0-81.4)\end{array}$ & $\begin{array}{c}11.1 \\
(0-94.6)\end{array}$ & 0.0061 & 0.0124 \\
\hline Anxiety & $\begin{array}{c}12.9 \\
(0-97.0)\end{array}$ & $\begin{array}{c}2.9 \\
(0-85.1)\end{array}$ & $\begin{array}{c}9.9 \\
(0-97.9)\end{array}$ & 0.0148 & 0.0115 \\
\hline Mood swings & $\begin{array}{c}18.0 \\
(0-97.0)\end{array}$ & $\begin{array}{c}2.3 \\
(0-43.0)\end{array}$ & $\begin{array}{c}11.6 \\
(0-93.1)\end{array}$ & 0.0256 & 0.0009 \\
\hline Crying & $\begin{array}{c}4.7 \\
(0-97.6)\end{array}$ & $\begin{array}{c}2.0 \\
(0-58.0)\end{array}$ & $\begin{array}{c}4.4 \\
(0-74.9)\end{array}$ & 0.0402 & ns \\
\hline Depressed libido & $\begin{array}{c}55.6 \\
(0-99.4)\end{array}$ & $\begin{array}{c}34.6 \\
(0-100)\end{array}$ & $\begin{array}{c}57.0 \\
(0-98.9)\end{array}$ & 0.0025 & 0.0009 \\
\hline Headaches & $\begin{array}{c}10.3 \\
(0-97.9)\end{array}$ & $\begin{array}{c}4.3 \\
(0-57.0)\end{array}$ & $\begin{array}{c}9.3 \\
(0-81.7)\end{array}$ & ns & ns \\
\hline Fluid retention & $\begin{array}{c}25.1 \\
(0-97.6)\end{array}$ & $\begin{array}{c}4.9 \\
(0-98.9)\end{array}$ & $\begin{array}{c}4.4 \\
(0-98.4)\end{array}$ & ns & ns \\
\hline Abdominal swelling & $\begin{array}{c}29.0 \\
(0-97.4)\end{array}$ & $\begin{array}{c}4.6 \\
(0-98.1)\end{array}$ & $\begin{array}{c}15.7 \\
(0-98.0)\end{array}$ & $<0.05$ & $<0.05$ \\
\hline Increased appetite & $\begin{array}{c}11.0 \\
(0-88.4)\end{array}$ & $\begin{array}{c}3.0 \\
(0-57.3)\end{array}$ & $\begin{array}{c}3.4 \\
(0-93.3)\end{array}$ & ns & ns \\
\hline
\end{tabular}

ns: $P \geqslant 0.05$.

\section{Discussion}

The premenstrual syndrome has been a source of much interest and controversy over the last decade and many aspects of this disorder remain so. Fundamental issues of definition and diagnosis continue to be debated whilst a high placebo response ${ }^{5}$ poses difficulty for therapeutic trials.

This study employed a definition of the premenstrual syndrome based on that of Steiner, Haskett and Caroll, ${ }^{6}$ modified in a manner compatible with $\tilde{\text { O }}$ that suggested by $\mathrm{O}^{\prime} \mathrm{Brien}^{7}$ to include somatic as $\underset{\omega}{ }$ well as psychological symptoms. Symptoms widely acknowledged to be typical of PMS were selected $\Theta$ for assessment, including irritability, anxiety, depression, breast tenderness, abdominal swelling, ? fluid retention and headache. ${ }^{8}$ Assessment of symptom severity was by means of visual analogue scales

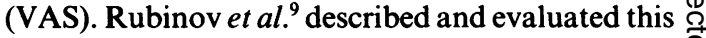
method and suggested that it was a simpler, more $\stackrel{\unrhd}{\stackrel{Q}{Q}}$ 
Table III Premenstrual scores: pooled data, irrespective of treatment order, including only scores related to last recorded menstruation on treatment

\begin{tabular}{|c|c|c|c|c|}
\hline Symptom & $\begin{array}{c}\text { Danazol } \\
(n=30) \\
\text { Median }\end{array}$ & $\begin{array}{c}\text { Placebo } \\
(n=29) \\
\text { Median }\end{array}$ & $\begin{array}{c}P v \\
\text { Danazol } \\
\text { vs } \\
\text { Placebo }\end{array}$ & $\begin{array}{l}\text { Danazol } \\
\text { vs } \\
\text { Baseline }\end{array}$ \\
\hline $\begin{array}{l}\text { Breast } \\
\quad \text { discomfort }\end{array}$ & 2.9 & 20.9 & $<0.01$ & $<0.01$ \\
\hline Irritability & 6.9 & 22.1 & $<0.01$ & $<0.01$ \\
\hline Depression & 2.9 & 12.9 & $<0.05$ & $<0.05$ \\
\hline Anxiety & 3.8 & 9.9 & $<0.05$ & $<0.05$ \\
\hline Mood swings & 1.8 & 12.6 & $<0.05$ & $<0.01$ \\
\hline Crying & 1.8 & 5.0 & ns & ns \\
\hline $\begin{array}{l}\text { Depressed } \\
\text { libido }\end{array}$ & 33.6 & 57.0 & $<0.01$ & $<0.01$ \\
\hline Headaches & 4.3 & 9.7 & ns & ns \\
\hline $\begin{array}{l}\text { Fluid } \\
\text { retention }\end{array}$ & 4.3 & 4.4 & ns & $<0.01$ \\
\hline $\begin{array}{l}\text { Abdominal } \\
\text { swelling }\end{array}$ & 4.7 & 15.7 & $<0.01$ & $<0.01$ \\
\hline $\begin{array}{l}\text { Increased } \\
\text { appetite }\end{array}$ & 3.3 & 3.4 & ns & ns \\
\hline
\end{tabular}

ns: $P \geqslant 0.05$

Table IV Patients' reports of adverse events

\begin{tabular}{|c|c|c|}
\hline Description & $\begin{array}{l}\text { Number } \\
\text { Danazol }\end{array}$ & $\begin{array}{c}\text { feports } \\
\text { Placebo }\end{array}$ \\
\hline Altered menses & 9 & 3 \\
\hline Nausea & 6 & 2 \\
\hline Headache & 2 & 0 \\
\hline Bloating & 2 & 0 \\
\hline Ankle swelling & 1 & 0 \\
\hline Acne/oily skin & 5 & 1 \\
\hline Increased facial hair & 0 & 1 \\
\hline Flushing/sweats & 1 & 1 \\
\hline Increased appetite & 2 & 1 \\
\hline Pruritus & 0 & 1 \\
\hline $\begin{array}{l}\text { Symptomatic exacerbation of } \\
\text { duodenal ulcer }\end{array}$ & 1 & 0 \\
\hline Total number of reports & 29 & 10 \\
\hline $\begin{array}{l}\text { No. of patients reporting adverse } \\
\text { events }\end{array}$ & 21 & 11 \\
\hline $\begin{array}{l}\text { No. of patients receiving } \\
\text { treatment }\end{array}$ & 33 & 31 \\
\hline
\end{tabular}

sensitive and more reproducible method than 3 or 5 point scoring systems. Comparisons between 'premenstrual' scores and 'rest of cycle' scores during baseline confirmed that the principal symptoms of PMS were indeed evident, and premenstrually exacerbated, in this group.

As there was no evidence confirming that benefit from danazol would extend beyond the course of treatment and the demands of the study were already high, no wash-out period was included. However, the possibility of a carry-over effect was given appropriate consideration in the statistical analysis.

Surprisingly, a high placebo response was not apparent in this study. In terms of overall response, only $22 \%$ of patients felt that their condition had improved with placebo. The reason for this relatively low placebo response is unclear but may relate principally to the study population. This group of patients had experienced PMS for a mean of 4.6 years and all 37 patients included in the study had received at least one medication for the condition before entering the study, several having received three or more different treatments. It is suggested, therefore, that such a population would be less likely to demonstrate a placebo response than one in which the majority of patients was receiving treatment for the first time. A further possibility is that response rates were determined at the end of each treatment phase by which time any possible placebo response may have waned.

In spite of the acknowledged difficulties in assessing the effects of medication in PMS this study clearly demonstrates that a $200 \mathrm{mg} /$ day danazol regimen improves most of the common symptoms of PMS as well as the patients perception of the overall severity of their condition. Although adverse complaints were more frequent with active treatment than with placebo, no serious reactions occurred. Significant androgenic changes were not seen and withdrawal because of suspected intolerance was infrequent.

It has been suggested that central to the effectiveness of danazol in PMS is suppression of menstruation. ${ }^{10}$ The significance of menstruation as a psychological trigger for symptoms of PMS has attracted previous work, given its supposed association with psychiatric disorders and neuroticism. ${ }^{10,11}$ This hypothesis was explored in this study by separately analysing the data relating to the last recorded menstruation on each treatment. This analysis confirms the efficacy of danazol and its action cannot, therefore, be dependent on the development of amenorrhoea.

In conclusion, low dose danazol ( $200 \mathrm{mg}$ daily) has been shown to provide effective treatment for most of the common symptoms of PMS and to improve the overall severity of the condition. Premenstrual improvement was not obtained at the expense of deterioration in the remainder of the cycle, nor was it dependent on the development of amenorrhoea. The treatment was associated with only minor side effects and was generally well tolerated. 


\section{References}

1. Muse, K., Cetel, N., Futternam, L. \& Yen, S. The premenstrual syndrome. Effects of 'medical ovariectomy' $N$ Engl $J$ Med 1984, 311: 1345-1349.

2. Gilmore, D.H., Hawthorn, R.J.S. \& McKay Hart, D. Treatment of the premenstrual syndrome: a double blind placebo controlled cross-over study using danazol. J Obstet Gynecol 1989, 9: 318-322.

3. Watts, J.F., Butts, W.R. \& Logan Edwards, R. A clinical trial using danazol for the treatment of premenstrual tension. $\mathrm{Br} J$ Obstet Gynaecol 1987, 94: 30-34.

4. Hills, M. \& Armitage, P. The two-period cross-over clinical trials. Br J Clin Pharmacol 1979, 17: 8-20.

5. O'Brien, P.M.S. Premenstrual Syndrome. Blackwell Scientific Publications, Oxford, 1987, pp. 124-126.

6. Steiner, M., Haskett, R.F. \& Caroll, B.J. Premenstrual tension syndrome: the development of research diagnostic criteria and new rating scales. Acta Psychiatr Scand 1980, 62: $177-190$.
7. O'Brien, P.M.S. Premenstrual Syndrome. Blackwell Scientific Publications, Oxford, 1987, p. 12.

8. Magos, A. \& Studd, J.W.W. The premenstrual syndrome. In: $\subseteq$ Studd, J.W.W. (ed.) Progress in Obstetrics and Gynaecology, Vol. 4. Churchill Livingstone, Edinburgh, 1984, ज़ pp. 334-350.

9. Rubinov, D.R., Roy-Byrne, P., Hoban, M.C., Gold, P.W. \& Post, R.M. Prospective assessment of menstrually related mood disorders. Am J Psychiatry 1984, 141: 674-686.

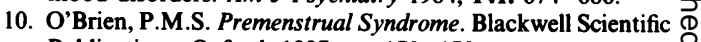
Publications, Oxford, 1987, pp. 170-172.

11. Coppen, A. \& Kessel, N. Menstruation and personality. $B r J$ ڤి Pscyhiatry 1963, 107: 711-717.

12. Endicott, J., Halbreich, V., Schacht, S. \& Nee, J. Premenstrual changes and affective disorders. Psychosom Med 1981 43: $519-529$. 